\title{
UTERUS BICORNIS BICOLLIS AND ITS SURGICAL CORRECTION: A CASE REPORT
}

Chandrashekar Murthy Y. M11, Shylaja D. K²

\section{HOW TO CITE THIS ARTICLE:}

Chandrashekar Murthy Y. M, Shylaja D. K. "Uterus Bicornis Bicollis and its Surgical Correction: A Case Report". Journal of Evolution of Medical and Dental Sciences 2014; Vol. 3, Issue 70, December 15; Page: 15007-15011, DOI: $10.14260 /$ jemds/2014/4018

\begin{abstract}
Bicornuate uterus is a type of uterine duplication anomaly. It is classified as a class IV Mullerian duct anomaly according to American Fertility Society (AFS) classification. The incidence of congenital uterine anomalies in a fertile population is $3.2 \%$. A 22 years old lady married since three years presented with History of three previous repeated abortions at 2 months, $2 \frac{1}{2}$ months and at 2 months of gestational age respectively and with $\mathrm{H} / \mathrm{O}$ dysmenorrhoea during menstruation. During the last miscarriage she was diagnosed to have Bicornuate uterus by abdominal ultrasonography. Patient was advised to undergo corrective surgery for bicornuate uterus. After six months of her last miscarriage Metroplasy surgery was done for bicornuate uterus and the defect was corrected. After six months of surgery she conceived again and the pregnancy continued beyond three and a half months.
\end{abstract}

KEYWORDS: Bicornuate uterus, Mullerian duct, Metroplasty surgery.

INTRODUCTION: Uterus Bicornis represents $26 \%$ of müllerian duct anomalies. Uterus bicornis bicollis is a condition where in the uterus will have two cavities with two cervix with or without vaginal septum. ${ }^{1}$ More than $50 \%$ of women with malformed uterus will stay completely asymptomatic. ${ }^{2,3}$ Patients with bicornuate uterus often presents with obstetric complicationsinfertility, early abortions, ectopic pregnancies, late abortions or premature birth, and IUGR. ${ }^{4}$ Offspring of mothers with a bicornuate uterus had a risk for congenital defects four times higher than infants born to women with a normal uterus. ${ }^{5}$

CASE REPORT: A 22year old lady came to the Out-patient Department of Obstetrics and Gynaecology, ESI Hospital, Peenya, Bengaluru. Her marital life was of three years. She had a history of three previous repeated abortions at 2months, $2 \frac{1}{2}$ months and at 2 months of gestational age respectively and history of dysmenorrhoea during menstruation since she attained menarche. After the last or third abortion she underwent thorough evaluation. All the blood tests were normal. She was also evaluated for immunological causes and inherited thrombophilia and found negative. There was no history of consanguineous marriage of her parents and no history of repeated abortions in any of the family members. She was the first child to her parents and her mother`s antenatal and natal period were uneventful. There was no history of Diabetes, Hypertension, RH incompatibility and TORCH group of infections.

Ultrasonography of abdomen and pelvis revealed Bicornuate uterus with endometrial Hyperplasia in both the horns. Metroplasty surgery was planned in view of her recurrent pregnancy loss. She was advised to come after six months of her last miscarriage. Modified strassmann Metroplasty Surgery was done and the defect was corrected. Post-operative period was uneventful. Uterus had healed properly. After six months of surgery she conceived again and her pregnancy continued beyond three and a half months. 


\section{CASE REPORT}

DISCUSSION: Mullerian duct anomalies result from defective fusion, canalisation or absorption of the median septum of the female reproductive system during embryonic development. The uterus is formed by the union of the two mullerian ducts at about the $10^{\text {th }}$ week. Fusion begins in the middle and then extends caudally and cephalad. The characteristic uterine shape is formed with cellular proliferation at the upper portion and a simultaneous dissolution of cells at the lower pole, thus establishing the first uterine cavity. This cavity is at the lower pole with a thick wedge of tissue above. The upper thick wedge of tissue (septum) is dissolved slowly creating the uterine cavity. This process is usually completed by the $20^{\text {th }}$ week. Any failure of fusion of the two mullerian ducts or failure to absorb the cavity between them persists in separate uterine horns or bicornuate uterus. ${ }^{6}$

\section{American fertility society has classified the mullerian duct anomalies as follows?:}

Class I: Müllerian agenesis or hypoplasia.

Class II: Unicornuate uterus.

Class III: Didelphys uterus.

Class IV: Bicornuate uterus.

Class V: Septate uterus.

Class VI: Arcuate uterus.

Class VII: Diethylstilbestrol (DES)-exposed uterus.

Fig. 1: USG showing Bicardinate uterus with two separate horns.

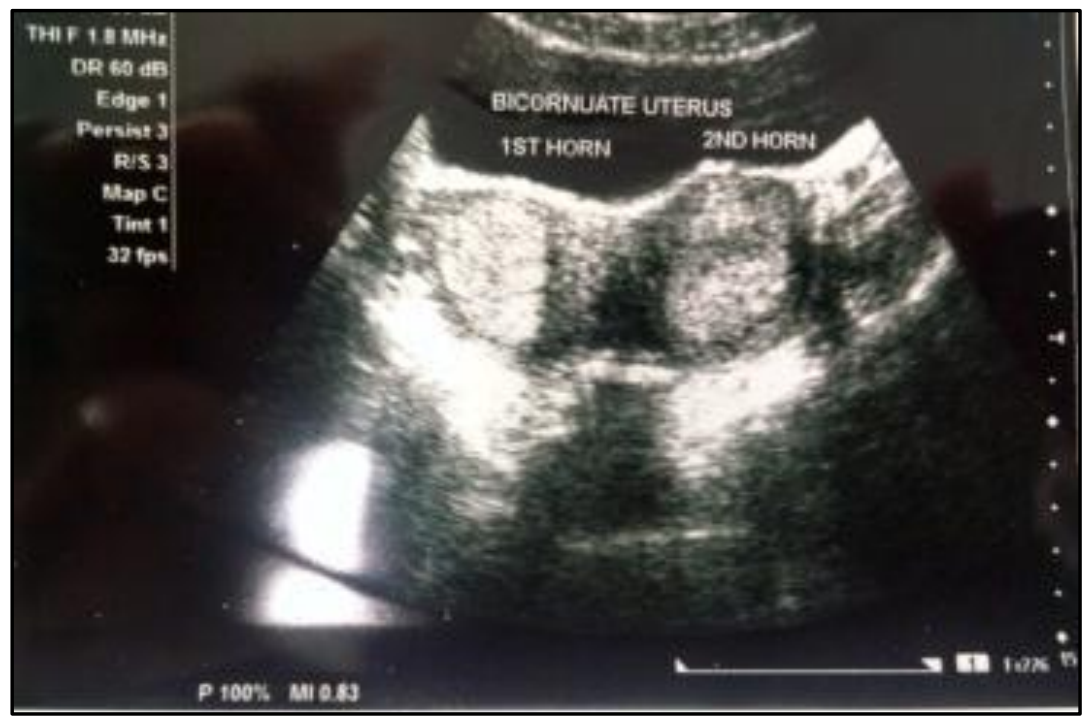

Fig. 1 


\section{CASE REPORT}

Fig. 2: The external uterine contour is concave or heart-shaped, and the uterine horns are widely divergent. The fundal cleft is typically more than $1 \mathrm{~cm}$ deep and the intercornual distance is widened.

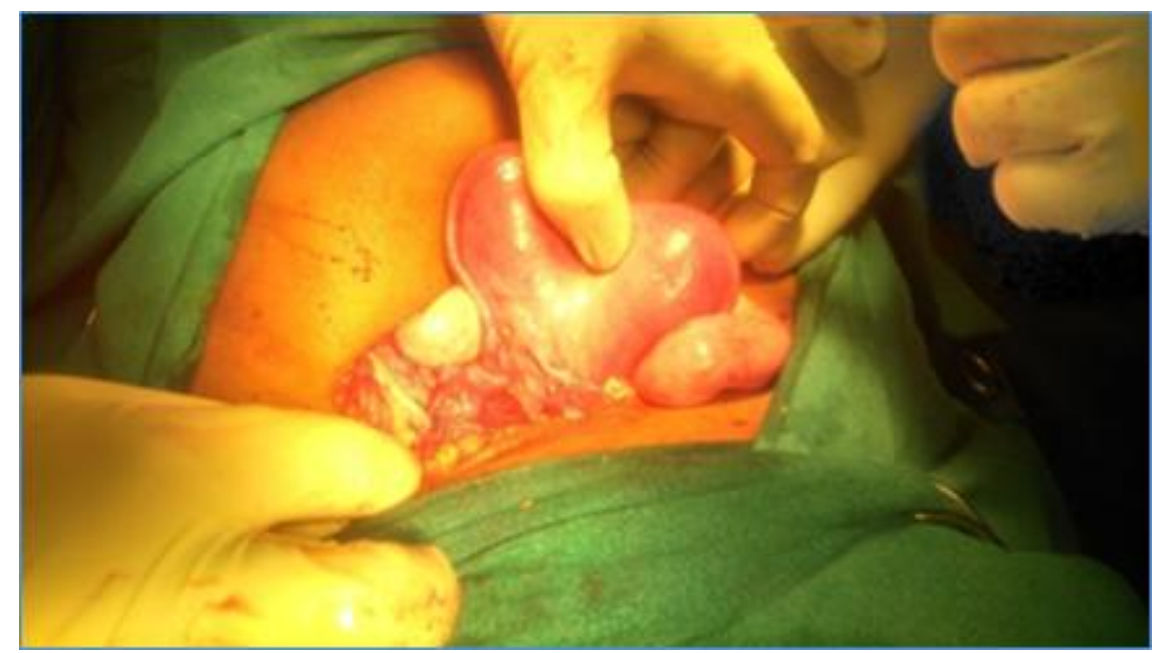

Fig. 2

Fig. 3: showing heart shaped contour of bicornuate uterus along with the ovaries.

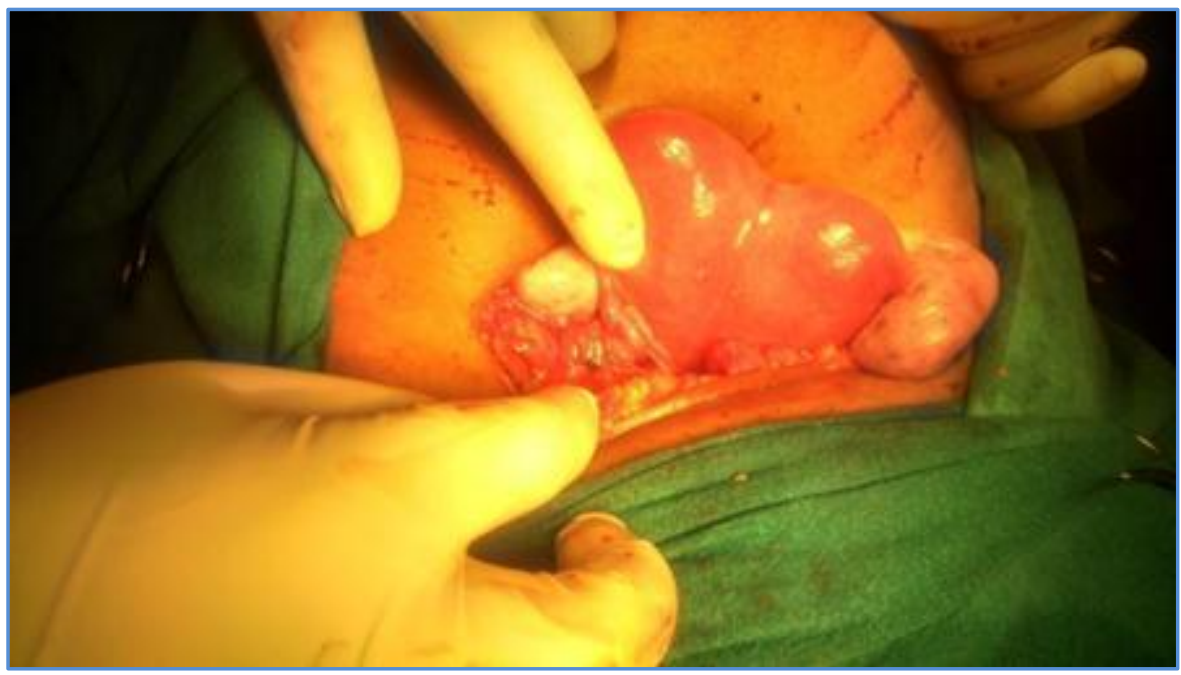

Fig. 3

Fig. 4: The fundal cleft is typically more than $1 \mathrm{~cm}$ deep and the intercornual distance is widened.

An incision is made on the medial side of each hemicorpus and carried deep enough to enter the uterine cavity. The edges of the myometrium will evert to face the opposite side. The myometrium is approximated to the other side edge by interrupted stitches using 2-0 vicryl and the serosa is sutured with continuous locking stitches using 1-0 catgut to maintain haemostasis and to avoid uterine tear. 


\section{CASE REPORT}

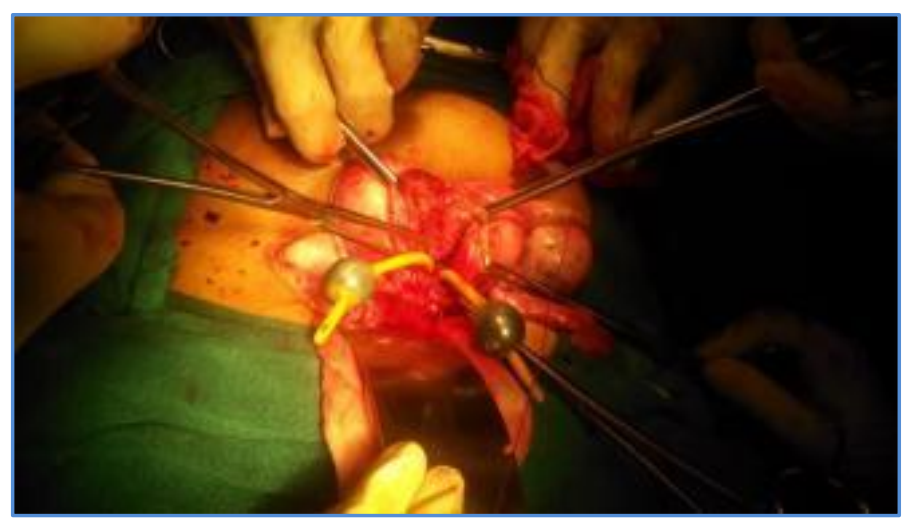

Fig. 4

Fig. 5: showing uterus after modified strassmann metroplasty surgery.

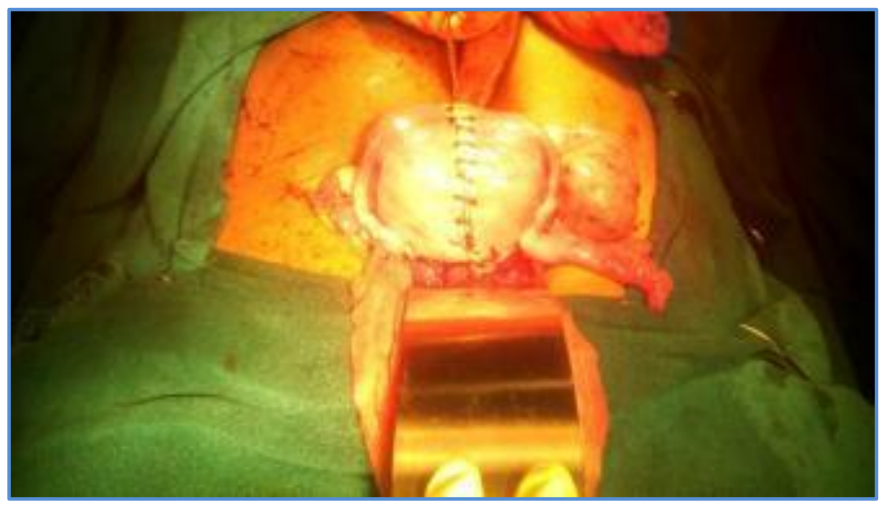

Fig. 5

Fig. 6: USG showing intra uterine pregnancy of 12 weeks 6 days.

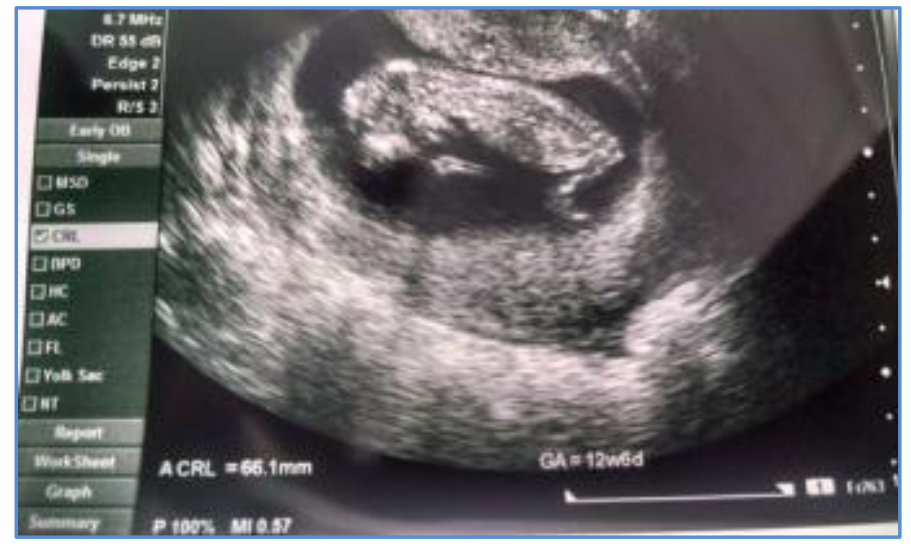

Fig. 6 


\section{REFERENCES:}

1. Dutta DC. Text Book of Gynaecology. Congenital malformation of female genital organs. $5^{\text {th }}$ edn. NCBA. 2009.43.

2. Green LK, Harris RE (1976) Uterine anomalies. Frequency of diagnosis and associated obstetric complications. Obstet Gynecol 47: 427-429.

3. Harger JH, Archer DF, Marchese SG, Muracca-Clemens M, Garver KL (1983) Etiology of recurrent pregnancy losses and outcome of subsequent pregnancies. Obstet Gynecol 62: 574581.

4. Howkins and Bourne Shaw's Text book of Gynaecology (14thedn), ISBN: 918- 81-312-1131: 8188.

5. María Luisa, Martínez-Frías, Eva Bermejo, Elvira Rodríguez-Pinilla, and Jaime Luis Frías. 1998: Congenital Anomalies in the Offspring of Mothers with a Bicornuate Uterus. Pediatr 2002; 101 (4): $\mathrm{p} 10$.

6. F Gary Cunningham et al. Williams Obstetrics.22nd edn. Mc Graw Hill.2005: 950-51.

7. American Fertility Society classification of mullerian anomalies (1988) Fertile Steril 49: 952.

\section{AUTHORS:}

1. Chandrashekar Murthy Y. M.

2. Shylaja D. K.

\section{PARTICULARS OF CONTRIBUTORS:}

1. Assistant Professor, Department of OBG, ESIC MC PGIMSR, Bangalore.

2. Assistant Professor, Department of Anatomy, Dr. B. R. Ambedkar Medical College, Bangalore.

\section{NAME ADDRESS EMAIL ID OF THE CORRESPONDING AUTHOR:}

Dr. Chandrashekar Murthy Y. M, \# 4/173/2, $2^{\text {nd }}$ Main,

Bovipalya, Mahalaxmipuram, Bangalore-560086,

Karnataka, India.

Email: drchandruym@gmail.com

Date of Submission: 06/11/2014. Date of Peer Review: 07/11/2014. Date of Acceptance: 08/12/2014. Date of Publishing: 15/12/2014. 